\title{
Rein Veidemann
}

\section{EESTI KIRJANDUSLIKUST MODERNISMIST A. H. Tammsaare modernism}

\begin{abstract}
Teesid: Artiklis keskendutakse modernismi kui kultuuridiskursuse vastuvõtule eesti kultuuriruumis. Modernismi mõiste muutus reljeefsemaks, kui 1960. aastatel võeti uuenenud kultuuripraktikate analüüsiks ja üldistamiseks kasutusele postmodernismi mõiste. Postmodernismi tõlgendamine on olnud vastuoluline. Selles on nähtud modernismi "hauakaevajat" ja uuele totaalsusele pürgivat metamõistet, teisalt on see ajendanud üle vaatama senist kultuuriteoreetilist diskursust. Eesti kirjanduskultuuris ei ole modernism ega ka postmodernism olnud nii laialt ekspluateeritavad mõisted kui lääne kultuuridiskursuses. 20. sajandi algul seostus modernismiga Eestis uusromantism. 19. sajandi lõpu kriitilist realismi esindavas Eduard Vilde loomingus võib leida modernismile omaseid jooni. Eripärasel viisil on modernismi tõlgendanud ja juurutanud ka Friedebert Tuglas. Eesti kirjanduslik modernism on vaadeldav metarealismina, mille eripäraks on lõpuleviidamatus, mitmete kujutamismeetodite segamine. A. H. Tammsaare looming sobib iseloomustama just seda tüüpi modernismi.
\end{abstract}

Märksõnad: Eesti 20. sajandi kirjanduslugu, Friedebert Tuglase ja A. H. Tammsaare looming, metarealism, modernism, postmodernism

Modernismi mõiste, selle suhestumine modernse tegelikkusega, tegelikkuse kujutamine modernismi paradigmas ja selles kujutatus modernismi äratundmine ehk teisisõnu modernismi eneseteadvus (metamodernism) - kõik see on ammu juba hakanud paistma kirjanduslike arutluste Minotauruse labürindina, mõiste modernism ise aga sellesse labürinti suletud Minosena, keda/mida postmodernism otsekui Theseus tappa üritab.

Või mütoloogilis-metafoorselt jätkates: sellest labürindist välja pääsemiseks "leiutatigi" Ariadne lõngana võetav postmodernism, mis orienteerub omaenda jäljele (enesekirjutusele) ja seejuures pidevalt vaatepunkti vahetades ehk simultaanselt kogu ühiskonna-, poliiti- 
Rein Veidemann

ka-, kultuuri-, kunstide (sh kirjanduse) välja erinevate tasandite, väljendusvahendite segamisele. Postmodernism on vastuoluline ja väga erinevaid arvamusi, autoreid ja teoseid sisaldav kultuuriline skaala, mille üks serv väljendab optimismi uutest võimalustest, samas kui teine äärmus suhtub nendesse arengutesse samavõrra skeptiliselt, tõdeb seni eesti keeles esimese ja kõige ülevaatlikuma postmodernismikäsitluse autor Janek Kraavi (Kraavi 2005: 15).

Määratu suurt modernismi ja postmodernismi alast kirjandust kas või üksnes ääri-veeri omandada tahtes leiab lugeja end õige pea Vilde Pisuhänna peategelase Tiit Piibelehe ütlusega silmitsi seisvat: nemad on igaüks ise endale pisuhänna leiutanud, mida nad nüüd palehigis arvustavad. Kõik see on loomulikult mõistetavgi, sest mida universaalsema kategooriaga meil tegemist on, seda suurem on selle kategooria emantsipeerumistung, nii et me ei märkagi, kui kategooria ise hakkab määratlema tegelikkust, selle asemel, et tegelikkus kinnitaks iseenda "kategoriaalsust".

Võimalik tõesti, et postmodernismi tulebki käsitleda diskursiivse mässuna modernismi totaliseerumisele, et tegemist on omamoodi metamõistega, koguni modernismi (auto)paroodiaga, mille poeetikalisi tunnuseid on analüüsinud näiteks Linda Hutcheon monograafias A Poetics of Postmodernism. History, Theory, Fiction (Hutcheon 1988). Postmodernism õpetab, et kõik kultuuripraktikad omavad ideoloogilist allteksti, mis määrab ära nende tähendusloome tingimused, väidab Hutcheon (Hutcheon 1988: xii-xiii). Ent sedasama võib ju põhimõtteliselt väita modernismigi kohta, mis oma kulminatsioonis (romantismiajastu kõrgmodernismina) väljendas teose enda võimet luua uusi realiteete mitte niivõrd tegelikkuse kirjeldamise, kuivõrd teose süntaktilise intensiivsuse läbi (eriti luules), nagu ütleb The New Princeton Encyclopedia of Poetry and Poetics (Preminger \& Brogan et al. 1993: 793). Teosekesksus, teose "tung" tabada oma müüdilist põhja, arheteksti ja saavutada 
seeläbi postmodernismi poolt troonilt tõugatud "suure narratiivi" seisust - see on võetav modernismi ideoloogilise alltekstina.

Kõige üldisemas plaanis võib modernismis näha teatavat vaheseisundit kunagise (ka "vanaks, traditsiooniks" nimetatud) jumalikust ettemääratusest ja hierarhiatest küllastatud (kultuuri)ajaloolise tegelikkuse (mis omakorda oli sotsiaalajalooliselt agraarne ja feodaalne, kuningavõimukeskne, selle viimases faasis aga ka juba inimeses jumalikkust avastavale renessansile toetuv tegelikkus) ning tänase, nüüd juba üle neljakümne aasta kestnud ja infoajastuna tõlgendatava tegelikkuse (mille paradigmaatiliseks esindajaks on arvatud "postmodernism") vahel.

Modernismi mediaansusest, vahepealsusest kultuuriseisundina tuleneb tema tõlgendusvõimelisus ja miks ka mitte kohanduvus, sest kõike uut, eksperimendiväärset manifesteerides võib alati tajuda ja esitada juba olnut "uuena". Vastuolust minevikuga ammutatud jõu abil artefakte ümber töödeldes või tõlgendades manifesteerib modernism end kui vanalt uuele ülemineku tulemust (Habermas 1996: 76).

Jürgen Habermas, kes on näinud modernismis selle n-ö ühele allikale taandamatust ja teisalt sellest tulenevat lópetamatustki, on kunsti arengus välja toonud progresseeruva autonomiseerimise liini: kõigepealt, kirjanduse, kunsti ja muusika institutsionaliseerimine, eraldumine sakraalsest ja õukondlikust elust 18. sajandil, seejärel estetistliku arusaama teke kunstist 19. sajandi keskel, siis esteetilise isemeelsuse muutumine eesmärgiks omaette 19. sajandi lõpul ja 20. sajandi algul, sealt edasi eesmärgivaba kunstinaudingu institutsionaliseerimine, kunstnike ja kriitikute estetistlik enesemõistmine ning kujutamisvahendite ja tootmistehnikate pürgimine ise esteetiliseks objektiks. Viimati loetletud muutused iseloomustavad 20. sajandit (Habermas 1996: 84-86) ja kujutavadki endast modernismi liikumist oma piirväärtuse poole. 
Modernismi algust kunstiliigiti loetakse erinevalt. Ühele momendile modernismi püsiva üleminekulisuse, mediaansuse kõrval - millele olen leidnud kinnitust J. Habermasi modernismi-käsitlusest tahaksin siiski tähelepanu juhtida.

Nimelt on tavaks saanud näha uuema aja filosoofia algust René Descartes'i 1637. aastal ilmunud Arutluses meetodist. R. Descartes'i ideaaliks oli selgus ja eristatavus. Ta tahtis luua universaalse teaduse, mis peaks tooma selguse kõigis teistes teadustes. See universaalne teadus pidi omakorda lähtuma neljast põhimõttest: 1) tunnistada tuleb ainult seda, mida on tõeselt tunnetatud ja mida ollakse võimeline selgelt eristama ning eksperimentaalselt tuvastama; 2) kõik tuleb lahutada paremaks tunnetamiseks osadeks; 3) tõeni jõudmiseks vajatakse teatavat korda, mis järgiks lihtsamalt keerulisema suunas liikumist ning 4) olemuse ja terviku uurimisel vajatakse loendeid ja ülevaateid (Koort 1996: 14-15).

Jätkem kõrvale selle ratsionalismi manifestiks peetava ideestiku otsese ülekandmisvõimaluse modernistliku kunstikontseptsiooni. Ometi ei saa märkamata jääda, et Arutluse... mitmedki elemendid on vägagi tähtsad modernismi "mootoris": uue avastamise kirg, teadvuse aktiivsus, eksperimentaalsus, terviku lahutamine osadeks. Ent veelgi tähtsam sarnasus näib seisnevat "metoodilisuses" endas, mille üksühest kattuvust näeme 20. sajandi vene formalistide manifestis kunst kui võte. Tõepoolest, kogu modernismi ajalugu võib võtta ka kui meetodite ajalugu. Modernismis teostub "uus" "uuena paistmise" kaudu. Paista laskmine, esile toomine sõltubki aga just meetodist. Niisama tähtsaks tuleb modernismis pidada seda, mida R. Descartes nägi põhistamas oma dualismi - teadmist inimvaimu autonoomsusest, teadmist sellest, et osaleme lõpmatusest (Koort 1996: 17). R. Descartes'ile tuginev valgustusideoloogia vormistas kaks suurt modernismi narratiivi - lõpmatu progressi ja inimese jumalikkuse, milles leidis aset ka modernismi eneselegitimatsioon. Selles mõttes mahub ka roman- 
tism modernismi alla, sest romantilises ideaaliski avaldub inimvaimu sõltumatus.

Tavaõiguslikult vastandatakse modernismi aga realismile, laiemas plaanis keelelist või igasugust vaimset kreatiivsust tegelikkuse passiivsele jäljendamisele, registreerimisele, fikseerimisele.

Eestis on modernismiga lood veelgi keerulisemad, iseäranis, kui jutt on kirjanduslikust modernismist.

Tuleb nõustuda Ele Süvalepaga, et Eesti kirjandusuurijad ei ole seda mõistet eriti armastanud (Süvalep 1998: 221). Eesti kirjanduslugudes esinevad küll aeg-ajalt sõnad modernism ja modernne, ent need on enamasti uue sünonüümid. Neis puudub kategoriaalne, mõisteline sisu. E. Süvalep küsib õigustatult, kas eesti kirjandusel on üldse modernismiga pistmist (Süvalep 1998: 222), viidates Tiit Hennostele, kelle 20. sajandi eesti kirjanduskäsitluse "Hüpped modernismi poole: eesti 20. sajandi kirjandusest Euroopa modernismi taustal" (Hennoste 1993, 1994, 1995, 1996, 1997) põhijärelduseks olevat see, et eesti kirjanduses, eriti sajandi alguspoolel, puudub selgelt jälgitav modernistlik arengujoon ja esinevad vaid üksikud "hüpped" modernismi suunas (Süvalep 1998: 22).

Siiski õnnestub E. Süvalepal veenda, et see, mida eesti kirjandusloos on kanooniliselt võetud kokku mõistega uusromantism, on vaadeldav ka varajase modernismina (Süvalep 1998: 226). Ta on täheldanud, et üks moderismi mõiste järjekindlaid kasutajaid on ise silmapaistvalt modernistlik kirjanik Jaan Oks, kes nimetas Friedebert Tuglastki modernistiks. Fr. Tuglas on küll seda terminit vältinud (Süvalep 1998: 224-225). Siiski on mitu vihjet, mis lasevad aimata, et kuigi Fr. Tuglas ei leidnud põhjust modernismi mõistesse mahutada oma kaasaegsete loomingut, kasutades selleks mitmeks alaliigiks jaotuvat uusromantismi (vanaromantism, uusromantism, romantism) ja tema enda loomingumeetodit iseloomustavat spirituaalset ja sünteetilist realismi (Undusk 1986: 31, 39), on ta siiski vaikimisi aktsep- 
teerinud eesti kirjanduse peavoolu arengut 19. sajandi lõpust alates kui modernismi võidukäiku eesti kirjanduses.

Noor-Eesti kogemust kokku võtvas ja üldistavas käsitluses, mis kannab sümptomaatilist pealkirja "Moodsa kirjanduse algus Eestis", seob Fr. Tuglas seda 1896. aastal ilmunud Eduard Vilde romaaniga Külmale maale (Tuglas 1936: 162). Selle kriitilise realismi küpsema esinemise ajalugu (Tuglas 1936: 162) sissejuhatava romaani lõpus on stseen, kus välk lööb ootamatult põlema kiriku ja uhke linnamaja, millest lugeja Fr. Tuglase arvates võis välja lugeda autori kriitilise hoiaku avaldamist sümboolse akti kaudu (Tuglas 1936: 164). Niisiis, kuigi kriitilise realismi tippteos, on siin ometi tegemist ühelt poolt romantismi sugemetega (Fr. Tuglase sõnul minevikus oli kaeveldud tuleviku nimel) (Tuglas 1936: 164), teisalt aga ka sümbolismiga.

Tuglase arvates selle ajastu ideoloogia - ilmplitsiitselt modernism - pole mingi eeskätt valmis kava, vaid kujuneb alles tegevas töös. Jätkuva loomingu orgaaniline kasvuloogika kujutab endast aga otsekui selle paisuva tüve kontsentrilisi ringe. See ajastu mõtte mõistmise ja vormimise kirg on jõud, mis arengut edasi kannab, resümeerib Fr. Tuglas nooreestlaste juurutatud eluhoiakuliste ja esteetiliste põhimõtete tähendust eesti (kirjandus)kultuuris (Tuglas 1936: 177).

Ootuspäraselt mahub Fr. Tuglase süsteemi ka Anton Hansen-Tammsaare, kes küll ise Noor-Eestist distantseerus, kuigi käis oma loomingulise tee hakul läbi uusromantismi kooli. 1918. ilmunud essees "A. H. Tammsaare" leiab Fr. Tuglas siiski, et A. H. Tammsaare pole olnud uue omandamisel piisavalt järjekindel. Kuigi A. H. Tammsaare looming, mis ülevaate kirjutamise hetkeks oli alles algusjärgus ja sisaldas külarealistlikku "Vanad ja noored", mõistukõnede kogumikku Poiss ja liblik ning üliõpilasnovelle "Pikad sammud", "Noored hinged" ja "Üle piiri”, vääris see Fr. Tuglase silmis tiitlit kui kõige rohkem ülevaatelist ainet sisaldav näitestik sellest edust, mis meie kirjandus viima- 
se aastakümne jooksul on üle elanud (Tuglas 1935: 83). Siiski tõdeb ta A. H. Tammsaare stiili igavust (Tuglas 1935: 101). Tema stiilil puudub aktiivsus [---]. Ta [st A. H. Tammsaare] ei lähenda meid inimlikkude tundmuste algallikale, vaid ainult refereerib neid (Tuglas 1935: 108).

On huvitav, et see, mida Fr. Tuglas A. H. Tammsaarele ette heidab, nn targutamist, saabki viimase kirjandusliku käekirja olemuslikuks jooneks. Niisamuti teinegi tähelepanek, mille Fr. Tuglas 1918. aastal samuti leiab puuduse olevat. A. H. Tammsaare pakkuvat õigupoolest ainult hingeelulisi paradokse ega mitte probleeme, tema toodangus ei kanna inimene igakord môtet, vaid paradoks kannab inimest (Tuglas 1935: 124). Hiljem selgub, et just paradoks on see, mis teeb Tammsaarest Tammsaare.

A. H. Tammsaare ebapuhtus, ebamäärasus, järjekindlusetus modernismi meetodis viib Fr. Tuglase järeldusele, et ta on naturalismi ja impressionalistliku uusromantismi vahepealne nähtus (Tuglas 1935: 128). Kolm aastat hiljem täitub see, millega Fr. Tuglas oma esimese essee A. H. Tammsaarest lõpetab: Aasta varem oleksin Tammsaaret teisiti mõistnud ja aasta hiljem kahtlemata niisama (Tuglas 1935: 136). Eesti 1921. aasta kirjanduse ülevaates ütleb ta A. H. Tammsaare näidendil Juudit olevat murranguline tähtsus (Tuglas 1922: 215). Ta oluline tunnus on soliidsus ja küpsus (Tuglas 1922: 218).

A. H. Tammsaarel on olnud aga Noor-Eestist oma ettekujutus. Kolm aastat enne Fr. Tuglase kirjutatud Tammsaare-portreed, 1915. aastal, kirjutab A. H. Tammsaare artiklis "Keelest ja luulest":

Noortel kibeleb midagi uut rinnas ja nad katsuvad sellest teistele uskumapanevalt teatada. Aga uuest rääkida on raske, temale kuju anda peaaegu võimata. Uue algus peitub sealpool teadvuse läve, hôljub mingisuguses müstilises unistuste udus ja nõnda laduvad noored arvamisele, et udusest ainult uduse keele ja uduste kujudega aimu võib anda (Tammsaare 1988: 222-223).

A. H. Tammsaare modernism lähtub plastilisest elukujutusest, milles elu enda faktid toovad esile juhuse ja paratamatuse, lõpliku ja 
igavikulise vastasseisu. Tema taotluseks on luua fatamorgaanalise plastilikkusega kujud, mis aastasajad elavaks jä̈̈vad (Tammsaare 1988: 235). Nad esindavad A. H. Tammsaare sõnul kõrgemas mõttes realismi, isegi sümbolismi, seda, mille kohta ta ise kasutab Johann Wolfgang Goethe määratlust ühest kirjast Carl Ernst Schubarthile: Alles, was geschieht, ist Symbol (Tammsaare 1988: 235). A. H. Tammsaare meelest oleks see mingisugune tõsine reaalsus, mis vahetpidamata liigub, muutub, aga ometi ei kao (Tammsaare 1988: 235).

Tänases kirjandusteoreetilises keeles võiksime selles näha metarealismi, st niisugust elukujutuslikku meetodit, mis pürib ühelt poolt oma psühholoogilise sügavuse ja panoraamsusega piirväärtuse poole (milleks on sümbol, ja see teeb temast modernismi paradigmasse kuuluva taotluse), teisalt aga ka eneseületuse poole iroonia ja paradoksi kaudu, mis otsekui tühistaks kujutatava tegelikkuse mõttekuse. Metarealism - see on ühelt poolt tegelikkuse tähenduse mitmekordistamine, teiselt poolt selle tühjendamine.

Nii muutub ka mõistetavaks A. H. Tammsaare metodoloogiline kaskaad, mida Jaan Kross on iseloomustanud kui laadilist mitmepalgelisust:

Tammsaare kui realist, kui nii-öelda vanarealist, süvarealist ja uusrealist, Tammsaare kui impressionist, kui uusromantik, aga ka kui jutustaja, kui heietaja, ja taas kui aforist. Ning hoiakuti, vahelduva dominatsusega erinevais teostes ja erinevail perioodidel, on ju olemas veel Tammsaare kui lüürik, Tammsaare kui satiirik, Tammsaare kui poleemik, Tammsaare kui filosoof (Kross 1982: 185).

Mõistetavaks saab ka, miks A. H. Tammsaare tõlkija ja üks säravaimad uurijad Friedrich Scholz on pealkirjastanud ühe oma Tammsaareuurimustest "Anton Hansen-Tammsaare (1878-1940). Eesti proosa realismi ja modernismi vahepeal" (Scholz 2001: 100-141). Niisiis taas see juba mitmel korral esile tulev "vahepealsus", millega kõigepealt sai iseloomustatud modernismi kui paradigmaatilist perioodi 
16. sajandi hilisrenessansist kuni 20. sajandi teise pooleni, "vahepealsus, üleminekulisus, mittetäielikkus", mis iseloomustab eesti uusromantismi erinevaid avaldusi ja mida võib täheldada A. H. Tammsaare juureski.

Kõik see viib mõttele, et eesti modernism - kui seda nimetada võtame ja siiski tunnistame selle kui 19. sajandi lõpul alanud ja 20. sajandi 1980. aastateni kulgenud kirjanduse peajoone olemasolu - ongi katse ületada selle meetodi sisemist heterogeensust, seda sünteesides ja eesti kogemusega kohandades. Euroopa modernismi suhtes marginaalne eesti modernism toimib väljakutsena sellesama Euroopa kirjanduse suhtes ja A. H. Tammsaare loomingus leidis see väljakutse kõige võimsama ja tunnuslikuma kehastuse. F. Scholz, kellele A. H. Tammsaare on euroopa kirjanik par excellence, kelle töödes kaleidoskoopiliselt peegeldub Eesti ja Euroopa kirjanduse käekäik meie sajandi esimesel neljal aastakümnel (Scholz 2001: 105), ei kahtle ka selles, et A. H. Tammsaare on oma loomingu algusest peale järgimas just euroopa modernismi peavoolu iseloomustavaid momente, nagu naturalismi (selle sugemeid leiab ta jutustuses "Kaks paari ja üksainus”), mõistukõnet, allegoorilisust ja sümbolismi (A. H. Tammsaare miniatuurid, mis koondatud kogumikku Poiss ja liblik), impressionismi, groteski ja antirealismi, mida F. Scholz leiab A. H. Tammsaare üliõpilasnovellides, ning paraboolsust, mida esindab läbimurdeteosena näidend Juudit (1921) (Scholz 2001: 108-112).

1921. aastal ilmunud Kõrboja peremeest võib võtta kui A. H. Tammsaare meetodi esimest sünteesi. F. Scholzi sõnul leiab siin realistliku külaelupildi edasiandmisel ja sümboliks võimendamisel kasutamist terve skaala varasematest väljendusvahenditest, nagu lüürilis-impressionistlik keel, kujundite võime tõusta sümboliteks, sisemonoloogilisus, ekspressiivne žestikulatsioon (Scholz 2001: 113). Ja seejärel juba Tõe ja ôiguse epopöa, mille juhatab sisse modernismi manifesti ja modernistide vennaskonda kuulutavuse näitajana Charles Baudelaire'ilt 
Rein Veidemann

laenatud moto: Imelises tundlikkuses mõotmatuseni avardatud iga tühisem lapsepõlve mure, iga väiksemgi rõóm saab hiljem kunstiteose aluseks täiskasvanule, ilma et see ise seda ette teaks (Undusk 1991: 491). Kuigi selle moto ohtlikku ligilähedust Thomas De Quincey Inglise oopiumisööja pihtimustele, kellelt Ch. Baudelaire oma teksti laenas (Undusk 1991: 494), peetakse vähetõsiseks kartuseks (Treier 2000: 15), ollakse ometi ühte meelt, et selles tsitaadis, motos, mis alati on kirjanikupoolne näpuganäitamine (Undusk 1991: 492), leiab rõhutamist lapse mikrokosmoses ja mälus säiliva makrokosmiline võimekus (Treier 2000: 40) ning kestva mööduvuse (igavese mineviku) aja kuristikku vajuva sündmustiku elavustamise allikas (Undusk 1991: 493).

Põrgupõhja uut Vanapaganat pole põhjust pidada ainult A.Tammsaare loomingu apoteoosiks, vaid see on ka eesti modernismi tähtteos. See on nii metarealism kui ka sümbolism, aga selles on ka maagilise realismi ettekuulutust. Sest just siin teostub see, mida Tiit Hennoste peab modernistile oluliseks: vabadus, eitamine, skepsis, müütilisus, maailma lagunemine, isakuju kadumine, ambivalentsus, kõleda ja hirmutava maailma tunne (Hennoste 1996: 149). Siin jõuab A. H. Tammsaare lõpuks tõdedeni, mis kehtivad kogu inimkonna kohta (Treier 2000: 41).

A. H. Tammsaare ja eesti modernismi erilisus ootab veel avastamist. Seepärast tundub ka kuidagi vaesestav lugeda uusimast eesti kirjandusloost Epp Annuse väidet:

Jah, muidugi, Tammsaarega saavutas eesti realism oma küpsuse, Tammsaare kaasaegsed tema taset saavutada ei suutnud, kui nad teda ka jäljendada pü̈̈dsid. [---] Nii tundub, et Tammsaare peamine osa meie kirjandusdiskursis on tema olemasolu - millest vôib soovi korral ka mööda vaadata (Annus 2001: 288).

Arvan vastupidist: eesti kirjandusdiskursuses on A. H. Tammsaare modernismil paradigmaatiline tähendus, millest ei saa üle ega ümber. 


\section{Kirjandus}

Annus, Epp 2001. Anton Hansen Tammsaare (1878-1940). Annus, Epp \& Epner, Luule \& Järv, Ants \& Olesk, Sirje \& Süvalep, Ele \& Velsker, Mart. Eesti kirjanduslugu. Tallinn: Koolibri, lk 275-290.

Habermas, Jürgen 1996. Modernsus - lõpetamata projekt. Akadeemia 1, lk 75-93. Hennoste, Tiit 1993. Hüppeid modernismi poole: eesti 20. sajandi kirjandusest Euroopa modernismi taustal Vikerkaar 10, lk 41- 50 \& 11, lk 62-66 \&12, lk 69-74.

Hennoste, Tiit 1994. Hüppeid modernismi poole: eesti 20. sajandi kirjandusest Euroopa modernismi taustal Vikerkaar 1, lk 74-77 \& 3, lk 41-49 \& 4, lk 7174 \& 5, lk 63-68 \& 6, lk 68-72 \& 7, lk 73-78 \& 9, lk 74-78 \& 11, lk 70-75 \& $12, \mathrm{lk} 63-68$.

Hennoste, Tiit 1995. Hüppeid modernismi poole: eesti 20. sajandi kirjandusest Euroopa modernismi taustal. Vikerkaar 2, lk 78-82 \& 3, lk 76-78 \& 4, lk 7884 \& 5/6, lk 131-136 \& 9/10, lk 124-130 \& 11, lk 87-94.

Hennoste, Tiit 1996. Hüppeid modernismi poole: eesti 20. sajandi kirjandusest Euroopa modernismi taustal. Vikerkaar 3, lk 69-76 \& 4, lk 86-93 \& 5/6, lk 142-149.

Hennoste, Tiit 1997. Hüppeid modernismi poole: eesti 20. sajandi kirjandusest Euroopa modernismi taustal. Vikerkaar 1/2, lk 115-127 \& 4/5, lk 144-153 \& nr 7/8, lk 152-161 \& 9, lk 101-107 \& 10/11, lk 142-149.

Hutcheon, Linda 1988. A Poetics of Postmodernism: History, Theory, Fiction. New York \& London: Routledge.

Kraavi, Janek 2005. Postmodernismi teooria ja postmodernistlik kultuur: ülevaade 20. sajandi teise poole kultuuri ja mõtlemise arengust. Viljandi: Viljandi Kultuuriakadeemia.

Kross, Jaan 1982. Vahelugemised 3: Kirjandusteoreetilised ja-kriitilised artiklid, sõnavõtudjms. Tallinn: Eesti Raamat.

Koort, Alfred 1996. Inimese meetod. Eesti mõttelugu 8. Tartu: Ilmamaa.

Scholz, Friedrich 2001. Anton Hansen-Tammsaare (1878-1940): Eesti proosa realismi ja modernismi vahepeal. Treier, Elem (koost). Tammsaare maailmakirjanikuna: Kolm välismaa Tammsaare-uurijat: [Veli Ilmari Mikkonen, Friedrich Scholz, Vladimir Macura]. Tallinn: Olion, lk 100-142.

Süvalep, Ele 1998. Modernismi alguse probleem eesti kirjanduses. Laak, Marin (koost). Traditsioon E pluralism: Kirjanduskonverentside materjale: Ettekan- 
deid, artikleid, esseidja eksperimendikirjeldusi eesti ja soome uuemast kirjandusteadusest. Tartu: Eesti Kirjandusmuuseum, lk 221-227.

Tammsaare, A. H. 1988. Publitsistika 2: (1914-1925). Kogutud teosed 16: Tallinn: Eesti Raamat.

Preminger, Alex \& Brogan, Terry V. F. et al. (toim) 1993. The New Princeton Encyclopedia of Poetry and Poetics. Princeton paperbacks. Princeton (New Jersey): Princeton University Press.

Treier, Elem 2000. Tammsaare ja tema "Tõde ja õigus". Tallinn: Olion.

Tuglas, Friedebert 1922. Kriitika IV. Tartu: Noor-Eesti.

Tuglas, Friedebert 1935. Kriitika III. Tartu: Noor-Eesti.

Tuglas, Friedebert 1936. Kriitika VI. Tartu: Noor-Eesti.

Undusk, Jaan 1986. Realismi mõiste ümber: F. Tuglase "realism" ja sajandivahetuse kultuur. Valminud uurimuse eeltrükk. Preprint (Keeleja Kirjanduse Instituut) KKI-46. Tallinn: Eesti NSV Teaduste Akadeemia.

Undusk, Jaan 1991. Tammsaare, Baudelaire ja De Quincey: “Tõe ja õiguse” esimese osa motost. Keel ja Kirjandus 8, lk 491-495. 


\section{VÕIM \& KULTUUR 2}

\section{Koostaja ja toimetaja Mare Kõiva}

http://www.folklore.ee/pubte/eraamat/voimjakultuur2/

Koostaja ja toimetaja: Mare Kõiva

Keeletoimetaja: Mare Kalda

Inglise keele toimetaja: Tiina Kirss

Makett ja kaas: Alo Paistik

Pilditöötlus: Andres Kuperjanov

HTML: Diana Kahre

ISBN 978-9949-586-83-7 (pdf)

ISBN 978-9949-418-53-4 (trükis)

DOI: $10.7592 / \mathrm{VK} 2.2006$

Tartu 2018

Trükis ilmunud: Võim \& kultuur 2. Koostaja ja toimetaja

Mare Kõiva. Võim ja kultuur. Tartu 2006

E-raamatu valmimist toetas: EKKM14-344 Eesti keele, kultuuri ja folkloori kasutusalade laiendamine ja tutvustamine elektroonilistel infokandjatel.
(C) 2018 Eesti Kirjandusmuuseum
(C) 2018 Eesti Folkloori Instituut
(c) 2018 EKM FO rahvausundi ja meedia töörühm
(C) 2018 autorid 